\title{
Marginalization of young people in society
}

\author{
Oksana Duchak \\ Faculty of Social Sciences, The John Paul II Catholic University of Lublin, \\ Al. Racławickie 14, 20-950 Lublin, Poland \\ E-mail address: oksana.duchak@gmail.com
}

\begin{abstract}
Modern society has a lot of issues which require immediate interference from the side of state policy and government. Special place among these problems takes the process of marginalization of young people which is caused by deformation of state and public institutions, destruction of social, cultural, ideological and political bases of life, loss of value orientations. Stereotypical presumptions about people, coupled with prejudiced views concerning specific religions and their followers, are dangerous with respect to the influence that these stereotypes can have on progress towards social integration and community cohesion. Research conducted on youth show that experiences of poverty, homelessness, racism, unemployment, abuse, addiction, gender preference and so on generally determine marginalization but not necessarily. The notion of social exclusion and social marginalization are enlighten in the paper and propositions for development of effective policy strategies to prevent marginalization are presented. This article deals with analyzing the determinants of social exclusion, ideology of marginalization, educational marginalization.
\end{abstract}

Keywords: marginalization; social exclusion; youth

\section{INTRODUCTION}

Modern society has a lot of issues which require immediate interference from the side of state policy and government. Special place among these problems takes the process of marginalization of young people which is caused by deformation of state and public institutions, destruction of social, cultural, ideological and political bases of life, loss of value orientations. Stereotypical presumptions about people, coupled with prejudiced views concerning specific religions and their followers, are dangerous with respect to the influence that these stereotypes can have on progress towards social integration and community cohesion ${ }^{1}$. Social exclusion produces negative consequences and long-term damage to the living conditions, social and economic participation, health status and emotional life of young people. It also leads to the intergenerational transmission of poverty ${ }^{2}$. Social status and social feeling of population,

\footnotetext{
${ }^{1}$ Experience of discrimination, social marginalization and violence: a comparative study of Muslim and nonMuslim youth in three EU Member States. European Union Agency for Fundamental Rights. 2010 p. 3.

${ }^{2}$ G. Paolini. Youth Social Exclusion and Lessons from Youth Work. Produced by the Education, Audiovisual and Culture Executive Agency. p. 4.
} 
including the young people are constitutive features of changes which appear in the society and define the level of society condition, which depend on possibility of youth realization and meeting their needs.

Political philosopher Iris Marion Young supposes marginalization is a growing problem in the developed nations:

"Marginalization is perhaps the most dangerous form of oppression. A whole category of people is expelled from useful participation in social life",

Research conducted on youth show that experiences of poverty, homelessness, racism, unemployment, abuse, addiction, gender preference and so on generally determine marginalization but not necessarily ${ }^{4}$. Almost one out of three young people between the ages of 18 and 24 is at risk of social exclusion and poverty in the European Union ${ }^{5}$.

The notion of social exclusion and social marginalization are enlighten in the paper and propositions for development of effective policy strategies to prevent marginalization are presented. This article deals with analyzing the determinants of social exclusion, ideology of marginalization, educational marginalization.

\section{THE NOTION OF SOCIAL EXCLUSION AND SOCIAL MARGINALIZATION}

The notion of social exclusion can appear at different levels of human life, affecting not only individual person but also the whole group and is a major problem in the world.

"Social exclusion" is a concept which can be characterized and developed in two ways. In a narrow sense it is used as a synonym for income poverty and refers to people who are not connected with the paid labour market or to people in low-wage work ${ }^{6}$. It can be understand broadly - it means much more than poverty, deprivation, income inequity or lack of employment. The matter is that social exclusion is multidimensional ${ }^{7}$. In contrast to poverty and unemployment which concentrate on households or individuals, social exclusion is mainly concerned with the relationship between the individual and society, and the dynamics of that connection ${ }^{8}$.

\footnotetext{
${ }^{3}$ I. M Young. Justice and the politics of difference. Princeton, NJ: Princeton University Press. 1990 p. 53.

${ }^{4}$ R. Omidvar \& T. Richmond. Immigrant settlement and social inclusion in Canada. Working Paper Series: Perspectives on Social Inclusion. Laidlaw Foundation. 2003.

${ }^{5}$ According to the latest data published by Eurostat, an estimate of $29,8 \%$ of young people in the 18 -24 age group were at risk of poverty or social exclusion in the EU in 2011. Data can be accessed at http://epp.eurostat.ec.europa.eu/portal/page/portal/employment_social_policy_equality/youth/indicators (access: 25. 10. 2013).

${ }^{6}$ R . Peace. Social exclusion: a concept in need of definition? „Social Policy Journal of New Zealand” 2001: Issue 16 p. 26.

7 The same.

${ }^{8}$ S. Klasen. Social exclusion, children, and education: conceptual and measurement issues. p.2.
} 
Social exclusion may be a part of capability poverty. A Scottish moral philosopher and a pioneer of political economy Adam Smith focuses on the deprivation involved in not "being able to appear in public without shame" is a good example of a capability deprivation, taking the form of social exclusion. It reflects the importance of participating in community life and according to Aristotelian understanding that the individual lives inevitable "social" life". The point of Smith is that inability to interact freely with others is a significant deprivation in itself and some types of social exclusion must perceive as constitutive components of the idea of poverty ${ }^{10}$.

Social exclusion is a process whereby individuals, groups or communities are pushed to the edge of society, cut off from community networks and activities, and kept from taking part fully on account of their poverty, lack of education, poor health or other disadvantages. This may be the result of discrimination or an unintended outcome of policies ${ }^{11}$. The reason for the social exclusion of young people are external and internal - their independence doesn't makes any possibility to change the situation.

Marginalization combines social exclusion and discrimination. It insults human dignity and it objects human rights, especially the right to live effectively as equal citizens ${ }^{12}$. Families, ethnic groups may be marginalized within localities. Marginalization is a shifting phenomena. For example, individuals may be satisfied with their social status at some period of time, but when social change takes place, they lose this status and become marginalized ${ }^{13}$. Social marginalization represents the influence on health condition. The impact goes in many directions which intertwinement is evident ${ }^{14}$. (see Figure 1.)

\footnotetext{
${ }^{9}$ A. Sen. Social exclusion: concept, application, and scrutiny. "Social Development Papers ", Asian Development Bank. 2000: No.1 p. 4.

${ }^{10}$ The same. p. 5.

${ }^{11}$ Volunteerism and Social Inclusion. An extract from the 2011 State of the World's Volunteerism Report, 2011 p. 3 .

12 S. Cornish. Globalization and Marginalization: Discussion guide to the Jesuit Task Force Report. Loyola Institute, Australian Jesuits. 2007.

${ }^{13}$ M Burton, C. Kagan, Marginalization, In: I. Prilleltensky and G. Nelson. Community Psychology: In pursuit of wellness and liberation. London: MacMillan/Palgrave 2003.

${ }^{14}$ C. Kagan, D. Burns, M. Burton, I. Crespo, R. Evans, K. Knowles, et al. Working with People who are marginalized by the social system: challenges for community psychological work.
}

Available at : http://www.homepages.poptel.org.uk/mark.burton/margibarc.pdf (access: 18. 03. 2014). 


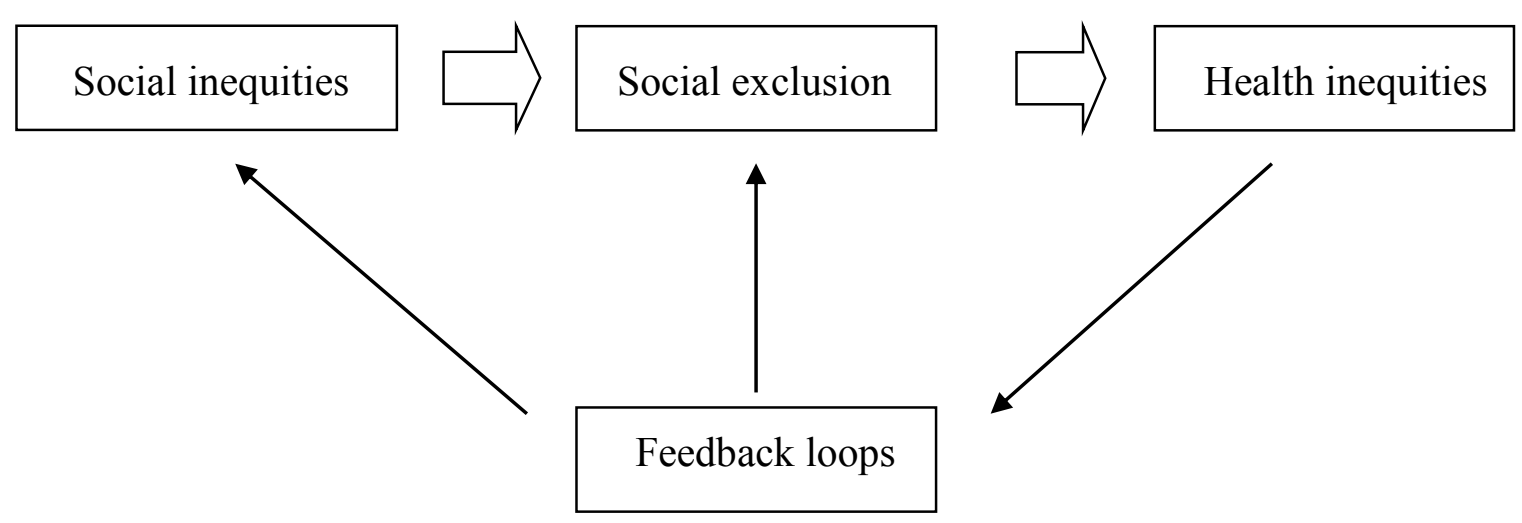

Figure 1.

Peter Leonard in his book "Personality and Ideology" defines social marginality as "being outside the mainstream of productive activity and/or social reproductive activity"15. This include two groups, a relatively small group of people who are voluntarily marginal to the social order (artists, commune members, religious sects) and group who are involuntarily socially marginal. Leonard characterizes these people as "involuntary social marginality"16. It is difficult to give a precise definition of marginalization. But, many previous studies have shown that it has a background of statistically measurable risk factors such as unemployment, lack of vocational skills and education, lack of family and social support, living in rent houses or living in unemployment area ${ }^{17}$.

\section{DETERMINANTS OF SOCIAL EXCLUSION}

The main determinants of social exclusion are: poor levels of education, living in remote geographical areas, discrimination because of monetary poverty, personal characteristics, unemployment, experience of juvenile delinquency. Ground on socio-economic position, individuals and groups experience differences in exposure and vulnerability to marginalization ${ }^{18}$.

By discrimination we usually mean the treatment of a person based on the group to which a person belongs, not taking into consideration personal achievements. Repetitive experiences of discrimination (based on various individual characteristics such as ethnic background,

${ }^{15} \mathrm{P}$. Leonard. Personality and ideology: Towards a materialist understanding of the individual, London: Macmillan 1984 p. 180.

${ }^{16}$ The same. p. 181.

${ }^{17}$ A . Antilla and A . Uusitalo (ed). Contemporary marginalization and exclusion of young people - whose reality counts? NUORA Publications, 1998: No. 10 p. 30.

${ }^{18}$ G. Paolini. Youth Social Exclusion and Lessons from Youth Work. Produced by the Education, Audiovisual and Culture Executive Agency. p. 6. 
gender, sexual orientation, religion, language) increase the probability of experiencing social exclusion $^{19}$. Data indicate that feeling discriminated because of gender and sexual orientation lead to poorer levels of emotional wellbeing and bad health condition. Amongst the determinants of social exclusion, inequalities based on sexual identity and gender seems to be the strongest factors inducing physical and emotional suffering amongst young people ${ }^{20}$.

In the life circle of socially excluded young people early school leaving and barriers to accessing quality education and training are common occasions, impacting their ability to secure comfortable living conditions, enjoy political and cultural participation, defend their own health and obtain assistance when necessary. Combating these problems has been the EU's aim in establishing the target of reducing the rates of early school leaving to below $10 \%$ as part of its EU2020 strategy ${ }^{21}$. Several studies on the consequences of school failure point out that dropping out of school can result in lower employment rates, lower lifetime earnings, worse health status, less risk aversion, and lower satisfaction of life ${ }^{22}$.

Unemployment is a powerful threat for young people which lead to psychological discomfort and low self-esteem. Absence education and work for a long period of time results in social and political marginalization of young people, strengthening the feeling of powerlessness and dependence. Being not in employment, education and training is also linked

\footnotetext{
${ }^{19}$ The same. p.7.

${ }^{20}$ The same. p.9.

${ }^{21}$ Council conclusions of 12 May 2009 on a strategic framework for European cooperation in education and training ('ET 2020’). OJ C 119. 28.05.2009 pp. 2-10.

${ }^{22}$ G. Psacharopoulos. The Costs of School Failure. Analytical Report for the European Commission prepared by the European Expert Network on Economics of Education (EENEE), 2007 p. 7.
} 
to risk behaviours, having consequences of worse health conditions and further social exclusion $^{23}$.

There are three types of social practices and attitudes which result in exclusion:

a) Mobilization of institutional prejudice: This refers to the existence of "a predominant set of values, rituals and institutional procedures that operate systematically and consistently to the benefit of certain persons and groups at the expense of others";

b) unruly practices: this refers to the gaps between rules and their implementation;

c) social closure: this is the way in which "social collectiveness seek to maximize rewards by restricting access to resources and opportunities to a limited circle of eligibles" 24 .

One can think of three main categories of the social aspect $\mathrm{s}$ of exclusion:

a) access to social services (such a s health and education);

b) access to the labour market (precariousness of employment as distinct from low pay);

c) the opportunity for social participation and its effects on the social fabric (greater crime, juvenile delinquency, homelessness, and so on $)^{25}$.

\section{IDEOLOGY OF MARGINALIZATION}

Poverty is one of the main reasons and one of the main consequences of marginalization. It is almost unavoidable characteristic of all types of marginalized population groups: the ones suffering from AIDS, persons with difficulties in individual development, convicts, persons with mental disorders, refugees, homosexuals, juvenile delinquents, homeless ${ }^{26}$.

The two dimensions of marginalization, such as disempowerment/social dislocation and poverty/economic dislocation, can be considered as primary material insults. Being a part of a marginalized group also brings the risk of some more psychosocial-ideological threats. The first is the definition of one's identity by others: the ideological definition of one's marginalized identity in the interest of the dominant groups in society. Besides, we can notice that the situation of the marginalized persons is portrayed as a result of their own characteristic features ${ }^{27}$.

The problems that people face are then seen as of their own making, or at least as inseparable from their particular nature. The phenomenon is naturalized, it can be understand not only as a social aspect, but as something which can to be expected in the person. This phenomenon has been called 'blaming the victim' 28 and it is part of a more general 'culture of

\footnotetext{
${ }^{23}$ G. Paolini. Youth Social Exclusion and Lessons from Youth Work. Produced by the Education, Audiovisual and Culture Executive Agency. p. 14.

${ }^{24}$ S. Kham. Topic guide on Social Exclusion. International Development Department. University of Birmingham. 2012 p.9.

${ }^{25}$ A. Bhalla and F. Lapeyre. Social exclusion: Towards an Analytical and Operational Framework. p. 419.

${ }^{26}$ C. Sagric, O. Radulovic and M. Bogdanonovic and R. Markovic. Social marginalization and health. p. 50.

${ }^{27}$ M. Burton and C. Kagan. Marginalization. In: I. Prilleltensky and G. Nelson (Eds.). Community Psychology: In pursuit of wellness and liberation. London: MacMillan/Palgrave 2003.
}

${ }^{28}$ W. Ryan. Blaming the victim. New York: Vintage Books 1976. 
blame $^{29}$. For example, it has been suggested that personality characteristics develop in a specific cultural context, for example a 'culture of poverty' in which destitution result in cultural patterns that are passed on and are no longer adaptive ${ }^{30}$.

\section{EDUCATIONAL MARGINALIZATION}

Educational marginalization is understood as the status of an individual that has an educational level sufficiently lower than average to feel like marginalized in the society in general and in the labor market in particular because of her/his educational gap ${ }^{31}$.

Before identifying the educationally marginalized, it is important to look at levels of educational attainment by country, age and gender. There are some facts worth noticing:

a) In some countries, education attainment is low by international standards, at all educational levels;

b) The share of individuals with primary education or below is in some countries still very high by international standards. In particular, those with primary education or below are $42 \%$ of men and $39 \%$ of women in Syria; about $15 \%$ for women and 9 $\%$ for men in Iran; about $25 \%$ of women and $14 \%$ circa of men in Egypt; $18 \%$ for both men and women in Kosovo; $18.5 \%$ for men and about $12 \%$ for women in Nepal;

c) In some countries, the share of university graduates is similar to that of more advanced economies (Egypt, Iran), whereas it is dramatically lagging behind in other countries (Kosovo, Syria). Azerbaijan, China, Mongolia, and Nepal are in an intermediate position.

d) In some countries women, experience a disadvantage with respect to men. This is in particular the case of Egypt and Iran, whereas in other countries, the share of women that attain primary education or below is greater than that of men;

e) With few exceptions (Azerbaijan, Egypt, Iran), women reach higher educational levels than men, in terms of high secondary and tertiary education ${ }^{32}$.

Education can be a source of exclusion and marginalization for young people and children, besides can involve problems. This is particularly the case if, for some children, it fails to meet the standard called for in the Convention of the Rights of Children of 'development

\footnotetext{
${ }^{29}$ B.A. Farber \& S. T. Azar. Blaming the helpers: The marginalization of teachers and parents of the urban poor. “American Journal of Orthopsychiatry” 1999: 69 p. 515-528.

${ }^{30}$ C. Kagan, D. Burns, M. Burton, I. Crespo, R. Evans, K. Knowles, J. L Lalueza and J. Sixsmith. Working with People who are marginalized by the social system: challenges for community psychological work. p. 7. Much of this paper is adapted from an expanded version of this paper, to appear as M. Burton and C. Kagan (in press). Marginalization. In: I. Prilleltensky and G. Nelson. Community Psychology: In pursuit of wellness and liberation. London: Macmillan/Palgrave.

${ }^{31}$ F. Pastore. Marginalization of young people in education and work: Findings from the School-to-Work Transition Surveys. Background paper prepared for the Education for All Global Monitoring Report 2012 p. 3.

32 The same. p. 4.
} 
of the child's personality, talents, and mental and physical abilities to their fullest potential'. In addition, educational policies can encourage social exclusion as being adults ${ }^{33}$.

\section{THE ROLE OF COMMUNITY PSYCHOLOGY FOR PREVENTING MARGINALIZATION}

Community psychology can be rather helpful and productive way to respond to the challenge of youth marginalization. Its work concentrates on critically using notions from the psychology of individuals to comprehend the processes that penetrate marginalized people. Besides, community psychology has to avoid two subsidiary mistakes: the neglect of the subjective experience of social actors and the individualization of social problems ${ }^{34}$.

It's worth mentioning the definition of community psychology, which reflects its significance:

"Community Psychology concerns the relationships of the individual to communities and society. Through collaborative research and action, community psychologists seek to understand and to enhance quality of life for individuals, communities, and society ${ }^{\prime 35}$.

Practice of community psychology is based on a philosophy of change and community psychologist being actively involved in community processes which try to understand them. Community psychology interventions are competently placed in the community in non-clinical settings. With prevention as a key point, the community psychologist indents to effect social change in a broad context, participating in the community itself and cooperating with other community members. Community psychologists' concentrates on the rights of people uses the privilege afforded them to effect change towards a more neutral distribution of resources, especially for those who may be marginalized. In addition, many psychologists believe that loneliness is the main problem which takes place among many people in Western society. That's why community psychologies try to encourage to build a community, participating in various communities as it increases the quality of life and emotional stability ${ }^{36}$.

\section{CONCLUSION}

Young people may be socially excluded suffering from material deprivation, social and emotional marginalization. "Social exclusion" is a concept which can be defined in two ways.

\footnotetext{
${ }^{33}$ S. Klasen. Social exclusion, children, and education: conceptual and measurement issues. p. 9.

${ }^{34}$ M. Burton, C. Kagan, Marginalization. In: I. Prilleltensky and G. Nelson (Eds.). Community Psychology: In pursuit of wellness and liberation. London: MacMillan/ Palgrave 2003.

${ }^{35}$ J. H. Dalton, M. J. Elias, \& A. Wandersman. Community psychology: Linking individuals and communities, Stamford, CT: Wadsworth 2001 p. 5.

${ }^{36}$ May be available at:

http://www.uml.edu/docs/Community\%20Psychology\%20\%20Guiding\%20Principles_tcm18-116910.pdf (access: 13. 03. 2014).
} 
In a narrow sense it is used as a synonym for income poverty and refers to people who are not connected with the paid labour market or to people in low-wage work ${ }^{37}$. In the second sense it means much more than poverty, deprivation, income inequity or lack of employment. Social exclusion is a process where individuals, groups or communities are pushed to the edge of society, cut off from community networks and activities, and kept from taking part fully on account of their poverty, lack of education or other disadvantages. Marginalization combines social exclusion and discrimination.

The main determinants of social exclusion are: poor levels of education, living in remote geographical areas, discrimination because of monetary poverty, personal characteristics, unemployment, experience of juvenile delinquency. Educational marginalization is understood as the status of an individual that has an educational level sufficiently lower than average to feel like marginalized in the society in general and in the labor market in particular because of her/his educational gap. The work of community psychologists concentrates on critically using notions from the psychology of individuals to comprehend the processes that penetrate marginalized people.

\section{Biography}

MSc. Oksana Duchak - PhD candidate at the Faculty of Social Sciences in general Pedagogy at The John Paul II Catholic University of Lublin in Poland. Scientific interests: family studies, psychology, media studies, methods of learning foreign languages, school pedagogy. E-mail: oksana.duchak@gmail.com

\section{References}

[1] Antilla A., Uusitalo A. (ed), Contemporary marginalization and exclusion of young people - whose reality counts? NUORA Publications. 10 (1998) 30.

[2] Bhalla A., Lapeyre F., Development and Change 28 (1997) 413-433.

[3] Burton M., Kagan C., Marginalization, In: Prilleltensky I., and Nelson G., Community Psychology: In pursuit of wellness and liberation, London: MacMillan/Palgrave 2003.

[4] Cornish S., Globalization and Marginalization: Discussion guide to the Jesuit Task Force Report, Loyola Institute: Australian Jesuits 2007.

[5] Council conclusions of 12 May 2009 on a strategic framework for European cooperation in education and training ('ET 2020'), OJ C 119. 28.05.2009 pp. 2-10.

[6] Dalton J. H., Elias M. J., Wandersman. A., Community psychology: Linking individuals and communities, Stamford, CT: Wadsworth 2001 p. 5.

[7] Experience of discrimination, social marginalization and violence: a comparative study of Muslim and non-Muslim youth in three EU Member States, European Union Agency for Fundamental Rights, 2010 p. 3.

[8] Farber B.A., Azar S. T., American Journal of Orthopsychiatry (1999) 515-528.

\footnotetext{
${ }^{37}$ R. Peace. Social exclusion: a concept in need of definition? „Social Policy Journal of New Zealand”. 2001: Issue 16 p. 26.
} 
[9] Kagan C., Burns D., Burton M., Crespo I., Evans R., Knowles K., Lalueza J. L., Sixsmith J., Working with People who are marginalized by the social system: challenges for community psychological work, p. 7.

[10] Kham S., Topic guide on Social Exclusion. International Development Department, University of Birmingham: 2012 p.9.

[11] Klasen S., Social exclusion, children, and education: conceptual and measurement issues, p. 2-9.

[12] Leonard P., Personality and ideology: Towards a materialist understanding of the individual, London: Macmillan 1984 p. 180-181.

[13] Omidvar R., Richmond T., Immigrant settlement and social inclusion in Canada, Working Paper Series: Perspectives on Social Inclusion, Laidlaw Foundation 2003.

[14] Paolini G., Youth Social Exclusion and Lessons from Youth Work, Produced by the Education, Audiovisual and Culture Executive Agency, p. 4-9, 14.

[15] Pastore F., Marginalization of young people in education and work: Findings from the School-to-Work Transition Surveys, Background paper prepared for the Education for All Global Monitoring Report 2012 p. 3-4.

[16] Peace R., Social Policy Journal of New Zealand 16 (2001) 26.

[17] Psacharopoulos G., The Costs of School Failure, Analytical Report for the European Commission prepared by the European Expert Network on Economics of Education (EENEE) 2007 p. 7.

[18] Ryan W., Blaming the victim, New York: Vintage Books 1976.

[19] Sagric C., Radulovic O. and Bogdanonovic M. and Markovic R., Social marginalization and health, p. 50. 